\title{
Ghost city phenomenon along China's high-speed railway grid
}

\section{Shenghuan Zhao}

Department of Architecture, Built Environment and

Construction Engineering,

Politecnico di Milano,

Via G. Ponzio 31, 20133 Milano, Italy

Email: shenghuan.zhao@polimi.it

\section{Dongqing $\mathrm{Ma}^{*}$}

School of Architecture Design and Art,

Dalian University of Technology,

Linggong Road 2, Ganjingzi District,

Dalian City, Liaoning Province, China

Email: madongqingve@163.com

*Corresponding author

\begin{abstract}
A fresh urbanism era appears in China with the development of high-speed railway (HSR). Voluminous numbers of local governments are designing and erecting novel cities oriented to the HSR stations with the objective of gaining benefits from the HSR system. Nevertheless, a huge number of these freshly erected districts or cities entail a tremendously high vacancy rate, thereby resulting in 'ghost cities'. The present paper commences with an outline of the China's urban HSR growth and the phenomena of ghost cities. After a literature review on worldwide urban HSR development, the reasons behind the 'ghost city phenomenon' in China are analysed. In the end, the study is concluded by proposing several suggestions for HSR development.
\end{abstract}

Keywords: land use; urban planning; city planning; regional planning; siphon effect; China.

Reference to this paper should be made as follows: Zhao, S. and Ma, D. (2017)

'Ghost city phenomenon along China's high-speed railway grid', Int. J. Sustainable Society, Vol. 9, No. 3, pp.210-225.

Biographical notes: Shenghuan Zhao is a PhD candidate from the Politecnico di Milano and also as a Visiting Researcher in the Liege University, Belgium. His main research fields include high-performance architecture and sustainable cities. He obtained his Bachelor's of Architecture in China 2009 and his Master's of Architecture from Polimi in 2016. During 2009 to 2014, he worked as a practicing Architect and participated at several landmark projects. He is also a LEED AP, qualified to deal with sustainable building certification process.

Dongqing Ma is a Master candidate from the Dalian University of Technology and also a visiting student in Politecnico di Milano. Her main research fields include heritage renewable and sustainable cities. She obtained her Bachelor's in Architecture in China on 2015. 


\section{Introduction}

The authors of this paper scrutinised the urban high-speed railway (HSR) planning in China and realised that until March 2017, 91 cities of 169 key territory-level cities entailing an HSR station are expected or erected to be fresh HSR cities. Then authors investigated 114 county-level cities and found that 52 of these 114 cities are in favour of the urban HSR erection. The present survey excludes four direct-regulated municipalities such as Taiwan, Xinjiang, Hainan and Gansu. Hada line (Harbin to Dalian) is the densest of all lines, with a total of nine novel cities out of the 23 total stops being hosted here. Another line stretching from Shanghai to Beijing (the Jinghu line) is composed of 17 novel HSR cities out of the summation of 24 stops. These lines can facilitate 12 cities in total in terms of investment proposals. Among them, four cities will receive the funding of around thee billion Chinese Yuan; four cities will receive five billion Yuan investment funds while the other four cities will receive above ten billion Chinese Yuan for investment.

These urban HSR development can be categorised into two classes in accordance with their scales: HSR cities and HSR zones. The primary category is the 'HSR city' that is a comprehensive city whose functions range from public and commercial services to housing services. While they are considered as cities, their administrative managements are still subordinate to the original city. According to the report of Chinese city scale level divisions (2014), the HSR city will belong to the first sub-category of small cities with a population between 20,000 and 50,000. 'Western New City in Changchun' was the very first HSR city planned by the local government back in 2008, extending from Changchun South station along the Hada line, covering an area of $13 \mathrm{~km}^{2}$. 'HSR zone' is the second classification and it is simply considered as a mono-operational segment of the inventive old city. A significant number of these HSR zones are composed of distinctive functions to entice investment. The local governments need to highly invest in the HSR city, with a vast number of them covering an area of more than ten square kilometres and the HSR zone is the least covering some square kilometres.

Investigated by the World Bank (2014), a significant number of cities have economically benefited from the HSR zone or the HSR city. In consideration of HSR erection, the Bengbu local government (Anhui Province) opted to have the preceding city planning modified, concentrate on the novel south-east district where the HSR would be hosted. Bengbu's HSR city covers $9.27 \mathrm{~km}^{2}$ while having a projected population of 200,000 . The operation is categorised into the animation industrial park, the headquarters economic zone, low energy domestic communities and the global outsourcing service zone. The total investment in public facilities reaches a total of 26.4 billion (Anhui Province). Subsequent to the launch of the HSR in 2011, there was a sudden upsurge of all real estate prices adjacent to the HSR station, stretching out as far as several key districts in Bengbu with the price peaking at 9,000 Yuan per square metre. Presently, there exist numerous high-level industry projects under construction within the industry park. The events subsequent to the HSR launch have seen the stepping up of the city's growth.

A vast number of HSR zones or HSR cities actually are trapped in the contrary condition against the city stated above. For the last two decades or so, the main technique embraced in Chinese construction was "erect it then people will come"; however, it is non-operative today. Various city governments overrated the capacity of their regions as 
well as the overall impact associated with HSR. Due to this, such novel 'HSR zones' and 'HSR cities' just became 'ghost cities'. What does it denote by saying ghost city? Shepard (2015) says, "an uninhibited city comprising of considerable visible remains". While Chinese ghost cities seem vacated right from the commencement and completion of new structures, there are no inhabitants, businesses and vehicles being driven, but new buildings. In that book written by Shepard (2015) and titled as Ghost Cities of China, the author categorises Chinese ghost cities as a "novel establishment that is operating at extreme under capacity or an environment defined by excessive availability of the space compared with the inhabitants or occupants. There has been an escalating rate of 'HSR cities' being dubbed 'ghost cities'. As of 2011, since the commencement of HSR operation, Changzhou's 'HSR city' has been characterised as a ghost city by the media frequently, particularly Wujin district orientating at HSR. Sometimes back in 2013, this city was involved in propaganda at State media CCTV (a national TV service), by running a special program identified as 'Changzhou a ghost city'. Based on the air content, there was a huge fraction of the vacant commercial apartments and this phenomenon intensifies in the farmlands of the city edge.

Figure 1 The location of ghost cities on a map showing the population change and HSR grid (see online version for colours)

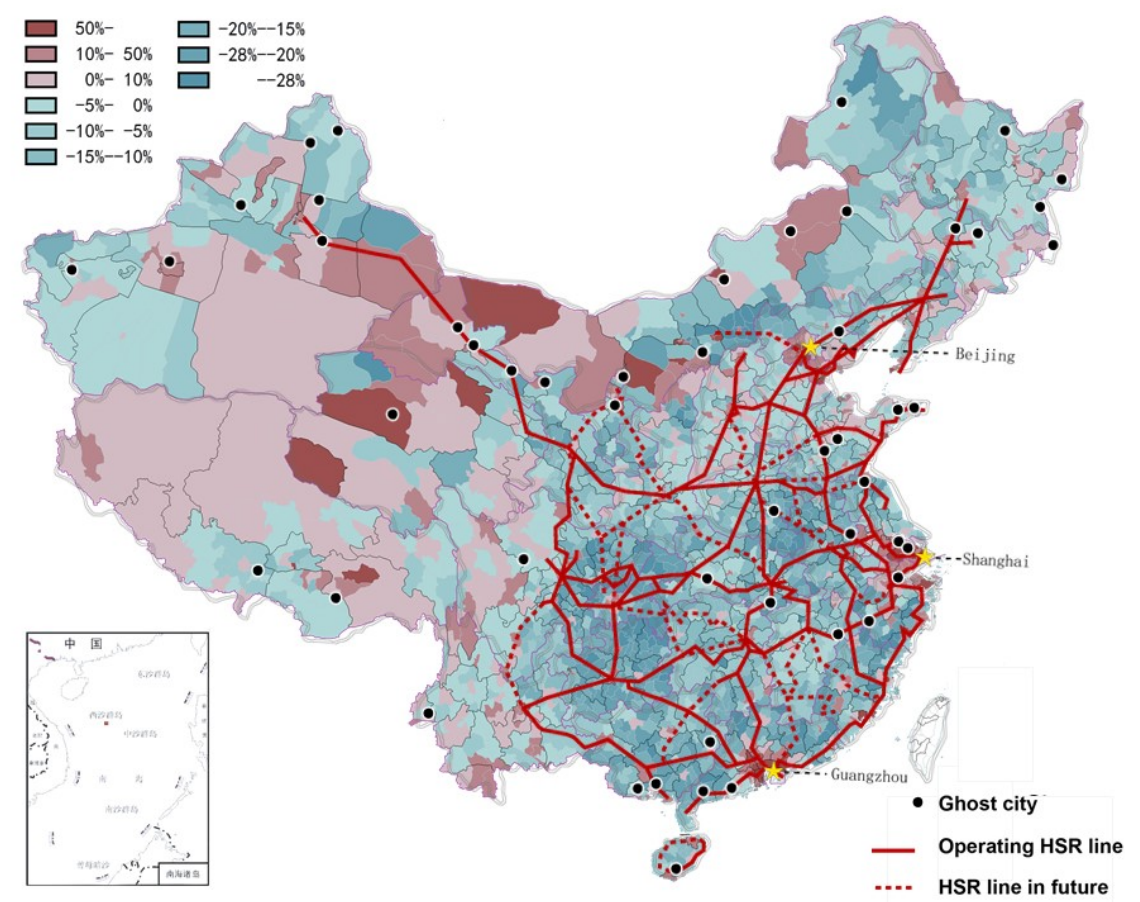

An official declaration of the HSR city of Suzhou (with $40 \mathrm{~km}^{2}$ of coverage area) confirmed that more than 100 projects have been imported. Presently, a number of projects have been subjected to standard erection with the rest being stopped. There has been an intense reluctance from the local government in the conversion of the HSR city into the ghost city; besides, the grand plan and the comprehensive investment will be halted. A significant amount of sunk costs will compel local officials to bump into 
'incompetent' critics, thereby terminating career promotion. The prevalence of ghost cities has always been detrimental. As is shown, establishing ghost cities is a waste of resources. The far worse situation is the collapse of the potential economic capacity behind the phenomenon of the ghost city. Among the salient indicators of evaluating the vigour of real estate in each city, the 'vacant housing frequency' exists. This indicator could be highly efficient in the identification of 'ghost cities' (Chi et al., 2015). Nonetheless, Chinese local governments and national governments of China have been reluctant to publish any information concerning the frequency of vacant properties since this would rescind the local economy besides being detrimental to the national economy. Some researchers have attempted to offer the spatial dissemination of Chinese vacant housing besides categorising cities with huge vacant housing coverage as tourism sites or cities, courtesy of Baidu positioning data (Chi et al., 2015). In accordance with a classification done by a private exploration company identified as Standard Research Institute (2016), about 50 cities have been considered as 'ghost city'. Upon situating these 50 cities on the map of China (Figure 1), it is evident that 22 cities are located in the HSR lines besides having HSR stops, and almost all cities have their HSR cities or HRS zones. A vast number of them are categorised under county-level cities and hold the lowermost administrative power, as far as the description of a city is concerned.

Table 1 The degree of 'ghost city phenomenon' in 22 cities on the HSR grid

\begin{tabular}{lccccccc}
\hline $\begin{array}{l}\text { Name of } \\
\text { the city }\end{array}$ & $\begin{array}{c}\text { Price 1 } \\
(C N Y)\end{array}$ & $\begin{array}{c}\text { Price 2 } \\
(C N Y)\end{array}$ & $\begin{array}{c}\text { Ratio } \\
(P 1 / P 2)\end{array}$ & $\begin{array}{c}\text { Name of the } \\
\text { city }\end{array}$ & $\begin{array}{c}\text { Price 1 } \\
(C N Y)\end{array}$ & $\begin{array}{c}\text { Price 2 } \\
(C N Y)\end{array}$ & $\begin{array}{c}\text { Ratio } \\
(\text { P1/P2) }\end{array}$ \\
\hline Zhangye & 3,700 & 3,772 & 0.98 & Maoming & 5,800 & 6,177 & 0.94 \\
Qingzhou & 4,008 & 3,669 & 1.09 & Chengde & 5,500 & 6,585 & 0.84 \\
Jiayuguan & 3,780 & 3,303 & 1.14 & Zhoukou & 4,000 & 3,435 & 1.16 \\
Yumen & 2,200 & 2,500 & 0.88 & Dehui & 4,736 & 4,032 & 1.17 \\
Tulufan & 1,000 & 5,000 & 0.20 & Quzhou & 9,257 & 8,261 & 1.12 \\
Weihai & 5,200 & 6,388 & 0.81 & Yantai & 9,000 & 7,496 & 1.20 \\
Wuzhong & 1,500 & 3,475 & 0.43 & Sanya & 18,000 & 20,375 & 0.88 \\
Kaiping & 1,500 & 4,204 & 0.36 & Taian & 5,415 & 6,292 & 0.86 \\
Guixi & 4,800 & 3,652 & 1.31 & Yichang & 5,300 & 6,149 & 0.86 \\
Chuzhou & 4,000 & 5,306 & 0.75 & Xianning & 2,500 & 3,050 & 0.82 \\
Haining & 9,000 & 9,283 & 0.97 & Lianyungang & 6,471 & 6,204 & 1.04 \\
\hline
\end{tabular}

This paper argues that since the ghost city is always linked to the vacancy of built units (Jin et al., 2017; Chi et al., 2015) and the housing vacancy rate is positively correlated with housing prices. It is equally logic to come up with an apt definition of the 'phenomenon of ghost city' based on the real estate price in 'new HSR cities' against the average price within the 'whole city in administration definition'. Being an incidental index, it is very feasible to obtain all the actual data. The present paper offers an analysis of the standard housing price in 22 HSR ghost cities and a clarification of the prices within the current HSR district as well as the entire city. Their difference ratio can be utilised in the popularity identification of the urban HSR in any city, besides determining the adversity of the ghost city phenomenon. All the information has been hosted by several websites such as 'fang.com', 'anjuke.com', 'cityhouse.cn', 'jiwu.com' and other local webpages, with time selection of November 2016. Price 1 and Price 2 are indicative 
of the HSR region's housing price and the entire city's average price, respectively. The data is available for both second-hand and new apartments, excluding the price of luxurious villa apartments. With reference to Table 1 , it is evident that 14 out of 22 cities suffer intense residential selling issue within the HSR cities or zones. On the other hand, five cities lack the novel HSR city erection, with the HSR region located in the original district located at the city centre, thereby an escalated price in comparison to the overall average price. 'Guixi', a single city has its HSR city within the trusteeship of Yingtan which holds an advanced level of administration and therefore its HSR zone equally holds a definitely higher price when compared with its original city of Guixi. Followed immediately by two cities Yantai and Dehui, their housing price is also very high when compared with the average price of the entire city. The two cities both lack mature up-to-date infrastructures in the old region.

\section{Literature review of HSR development in other countries}

The HSRs have been delineated by the 'European Transportation Policy' in the early '90s as a central aspect of the investment strategy (Pedro and Silva, 2013). While examining the impact of HSR networks on expansion, Vickerman (1997) stipulates that even though the network is composed of concentrated systems in central metropolitan centres, there is still a shortage of HSR network assimilation. Some ambiguities equally exist on the supposition of local development, progress, economic assimilation and social cohesion. In accordance with Banister and Berechman (2000), it is evident that 'Shinkansen' in Japan was able to wield a firm centralising impact on employment. On the contrary, other studies have concentrated on the requirement justification of HSR, by arguing the need to have a sample of 40,000 passengers on daily basis between two distant cities (Vickerman, 1997). Nonetheless, as stated by Sands (1993), while analysing HSR development and concentrating on TVG, Shinkansen and ICE, it is evident that having employment and community linked to HSR network regions will always draw additional employments and population settlement. In a study conducted by Ishikawa (1985), it is evident that besides simply relying on the HSR, the regional growth highly depends on the regional power. Nonetheless, Givoni (2006) confirmed the ambiguity involved in the evaluation of HSR growth that exclusively relies on the economic progress.

The outcome of the research reveals two key deductions. The first deduction is that the state-wide impact of HSR on cities are varied, indicating one to two hours from London, thereby facilitating the creation of renewed economies, although this impact has not been universal or automatic. A one-hour distance would be beneficial to HSR towns situated some distance from London by utilising both intrinsic and commuting economic power in events with exhaustive knowledge; one-hour HSR approachability highly benefits from utilising the economic roles. The effect of anything past two hours weakened. From a regional point of view, an HSR hub position has highly reinforced the key regional cities, although the impacts have failed to fully assimilate into the adjacent sub-regions. It is important to correctly assimilate HSR into regional and urban transport networks and therefore a spatial-economic association exists between a regional facility and its locality, thereby being adapted to generate and heighten the wider impacts. The second deduction is that transport alone is insufficient to establish the extensive impacts on minimising regional disparity. There is indispensability of complementary measures. There are five resulting factors that are considered highly important and they are 
constitutional capacity, nationwide political economy, planning precedence and resources, economic trajectory and type of the city and governance and leadership. Founded on the aforesaid setting, with an exceptional shrinkage of space and time, HSR will certainly have an enduring broader impact on the setting of economic accomplishments, instantaneously at state-wide (inter-regional), local (intra-urban) and regional (intra-regional) extents.

The assessment between the UK and France reveals how the French state-governed method defined by its decentralisation procedure indicates favourable circumstances, while the UK market-operated technique brings about inhibited and deprived settings for local intervention. These two experiential assessments are cautiously steered and founded on comprehensive interviews and policy scrutiny, capable of additionally establishing the interface between state-wide and local conditions besides aiding the understanding of distinction effect between and within two regions. The initial French TGV between Lyon and Paris resulted in the shifting of headquarters from Lyon to Paris, with the Spanish Madrid-Barcelona AVE combining the spatial transfer of its headquarters towards Madrid (Puga, 2002). Nevertheless, these methods inclusive of demand-driven, cost-oriented and past-dependent methods fail to take the active form of urban and regional growth linked with dissimilar government intervention into consideration.

In the studies about Japan, Amano and Nakagawa (1990) (cited in Sands, 1993), as well as Nakamura and Ueda (1989), the identified increased population growth in cities offers Shinkansen service in comparison to those that does not offer the service. Nonetheless, Sands (1993) showed controversy on the causal direction. These studies were able to report employment development as well, although there were differential impacts which were highest in service sector occupation, such as knowledge-founded sectors, with this remaining true even during the control for the instantaneous extension of the expressway network (Brotchie, 1991). In general, these studies are indicative of increased population growth rates and economic effects, which include economic activities and the employment for towns on HSR routes compared with the bypassed ones, founded on a time series prior and subsequent to the HSR services. Nonetheless, such impacts were extensively focused in tourism-concerned performances. While Nakamura and Ueda (1989) indicated and increased the association between increased growth rates in information-exchange occupation and the existence of HSR stations and a thruway, it is not clear when concerning the gap effect between such HSR cities and their capability of generating the extensive spatial-economic effect on less-deprived areas. A typical illustration of such associated problems is the intra-regional effect of HSR; with this concern being extensively overlooked, the emphasis has been placed on the effect on distinct cities instead of several cities within an expanse.

The constraints of administrative divisions have been overruled by the regional cooperation. The guiding role of the national government is evident in macro-control while the local governments endeavour to fully comprehend the economy of the huge region to assimilate a range of economic resources within the market. Cities are expected to show effort in attaining the labour division and resource compliantly to attain progress in a win-win state. Japan has offered a typical illustration of the excellent strengthening of the regional cooperation when avoiding 'siphon effect'. Prior to the launch of the Japanese 'HSR Shinkansen line' back in 1964, Nagoya was simply not a famous town. Upon its assimilation in the 'Tokyo one-hour metropolitan region', Nagoya started to centre on the expansion of automobile manufacturing, textiles, electronics and trade 
among other progressive manufacturing and up-to-date services while Tokyo was concentrating on being a research, design and financial centre. Presently, Nagoya is regarded as the largest city in Japan's Chubu region. Besides, being the third-largest assimilated city, it is the fourth most densely inhabited township in Japan. Each city along the HSR lines in Taiwan was subjected to an exclusive planning. In case of richness in agricultural products in a given region, this city is expected to establish wholesale markets for such products and institute some factories to engage in agriculture deep processing.

\section{The analysis on the causes of the ghost city phenomenon}

\subsection{Characteristics of the HSR city}

\subsubsection{The scale of urban HSR}

Efficient HSR city should be in a proper scale to fit the situation of the original city. There is equally the need to have the public services built in accordance with the specifics of the city scale. Therefore, for small or middle cities, the idea of 'HSR zone' is highly practical in comparison to the HSR city. However, there exist several illogical illustrations. In consideration of Jiaxing of Zhejiang province, a middle sized city roughly with a fifth of the entire population in comparison to Shanghai (its adjacent neighbour), has designed an HSR city whose size is slightly larger than the HSR city of Shanghai. Presently, a number of local governments have conferred the existence of ghost city phenomenon. In accordance with a study conducted by a researcher (Bao, 2014), a small city adjacent to Suzhou known as Dingyuan was strategised by the local government to have an HSR zone covering only 2 sq. km since they had already examined various HSR cities to avoid building another ghost city.

\subsubsection{Urban planning of the HSR city}

The space adjacent to the station is considered as the central point of an HSR city. This is delineated as the space including the railway station structure; a collection of the station building(s) and its instant (urban) settings are composed of open and built spaces (inclusive of transport infrastructure), in addition to their definite functional and physical characteristics. Nonetheless, the margins of such a region are indefinite since the impact range of the stations is uncertain (da Conceicao, 2015). The state council of China enacted a document concerning the growth if the regions are along the railway. What it means in the development area covers 'adjacent station area' granting the mission and upholding 'assimilated land development', the novel style urbanisation (China, 2014). The railway construction corporation's headquarter is in a preparation of exploiting the grounds along HSR so as to have the debt (loaned sometimes back for the purposes of HSR erection) repaid. As far as the space shape is concerned, the HSR city has a distinct feature due to the isolation of the HSR line. With the HSR initially being designed to take a double approach, one side faces the inventive city while the second one is on the opposite side of the railway. The frontal part holds a better association with the old city; therefore its constructed area's radius can be larger when compared with any other part to comprise more functional blocks. 
In case the HSR urbanism simply focuses on housing communities, the hazard of real estate failure and the risk of the ghost city phenomenon will go up. Meanwhile, inflexible land planning would limit the pace of development (Allin, 2011). The transit-oriented development (TOD), a technique of urban centring on exhaustive land use, public transportation, coordination of city growth planning, ecological assimilation and people living is a solution to this issue. The research on Chinese HSR cities and TOD theory has been recently conducted by diverse scholars. China illustrates a definite test bed to assess the diffusion as well as the political and scientific appropriation of the TOD concept (Doulet and Delaunay, 2016). In their study titled 'Rethinking human capital, creativity and urban growth', Storper and Scott (2009) investigated whether jobs trail people or people trail jobs. The authors opine that the modern tactic of urbanisation and in particular Florida's (2002) creative class notion, benefits the function of distinct locations as catalysts of personal growth and urban development.

\subsubsection{The homogeneous industry mode}

One evident reason behind the phenomena of ghost cities is low employment in the freshly erected HSR city, which is closely associated with a city's types of industry. The strategy of industry growth defines economy and the rate of vacancy of the HSR Township. Besides achieving integration, HSR contributes to the geographical closeness of cities. Under this condition, several small cities have competed against each other due to identical emergent plans and escalating modes. Much attention has however been paid to the urban novel HSR growth as well as the shortage of assimilation with the typical industries for local governments. Constraints subjected to administrative divisions have been broken by HSR. Therefore, the region's competition is highly market-driven. The size of any market is determined by the distance that the clients are willing to travel to acquire the specific product. For example, a typical grocery store merchandising products that lack high differentiation may be located at all places in minimal intervals. However, apple specialist stores and high-level hotels are situated at greater distances from each other, in consideration of extremely differentiated goods, like universal financing facilities and the market size is quite extensive. Therefore, in a case of the preference of two HSR cities which are identical while the market length is longer than the city margins, the competition ought to be considerably high. On the other hand, in case the market radius of the production is shorter compared with the city boundary, the HSR benefits are not employed and it is inconsequential to have the industry located in the HSR area (Figure 2). In accordance with survey, there ought to be a number of HSR cities that will both thrive in the competition due to numerous overlapping industries. Therefore, once the agglomeration is formed in the biggest city, there would unlikely be another in this region. In other words, the whole region is a single market area. The competition will be among regions rather than cities. Therefore, the national government is highly significant in macro control while the local government seeks to entirely comprehend the big region's economy so as to prevent competition besides assimilating various economic resources within the market. Cities are expected to try and meet the resource and labour division compliantly. 
Figure 2 The diagram on competitiveness of the HSR city (see online version for colours)

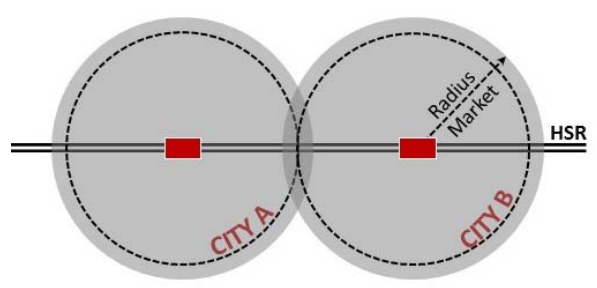

COMPETING CITIES

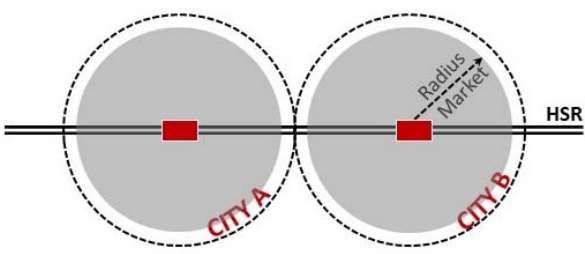

NON-COMPETING CITIES

Figure 3 'One-hour traffic circle' among Huhang line (Shanghai to Hangzhou), Ninghang line (Nanjing to Hangzhou) and Huning line (Shanghai to Nanjing) (see online version for colours)

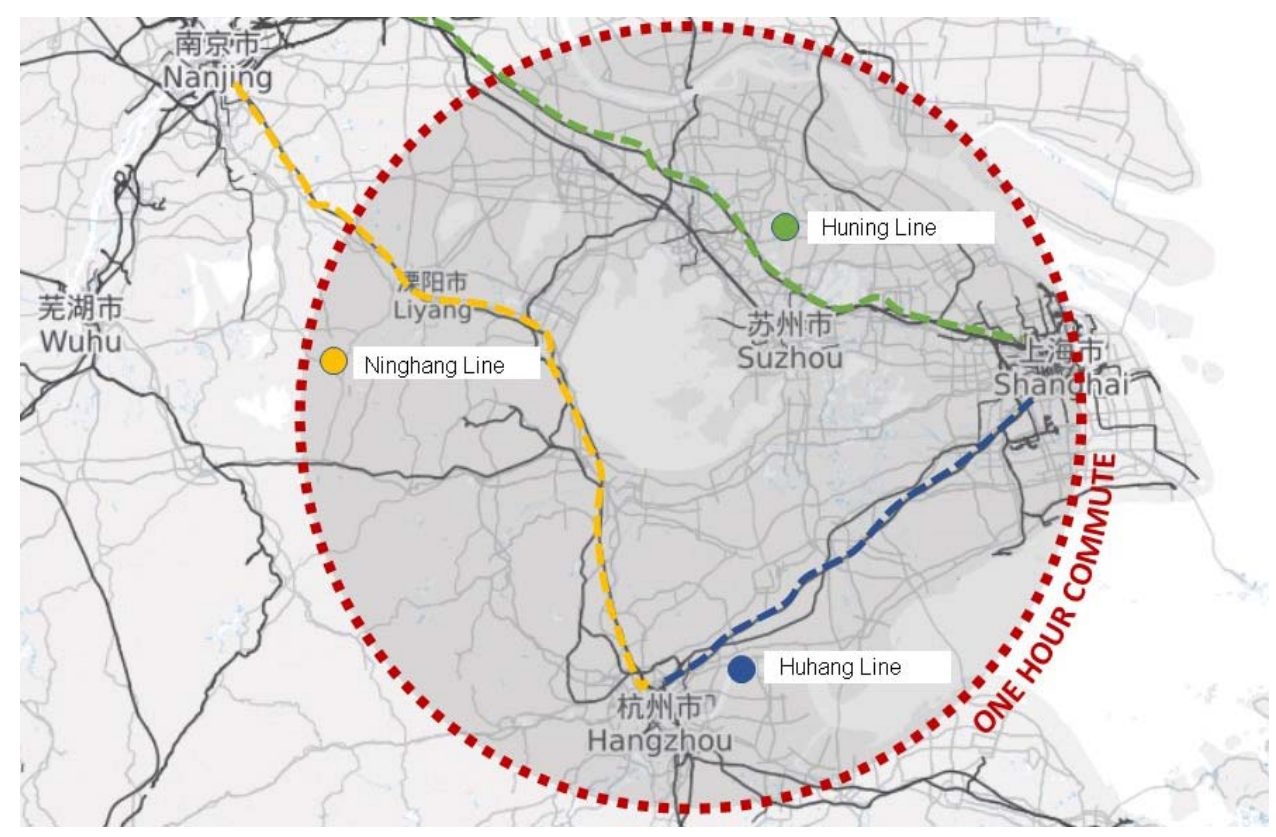

The Yangtze River Delta is the most developed areas in China, covering approximate 211,700 sq. $\mathrm{km}$, about $2.2 \%$ of the entire Chinese territory. It has a population of 0.15 billion and occupies about $11 \%$ of the state-wide population. Its GDP in year 2014 was 126,700 billion Yuan, totalling $18.5 \%$ of the national GDP which is slightly higher than that of Italy (Commision, 2016). Subsequent to initiation of Huhang line (Shanghai to Hangzhou), Ninghang line (Nanjing to Hangzhou), as well as Huning line (Shanghai to Nanjing), the central cities in the Yangtze River Delta are closely linked by HSR and 'one-hour traffic circle' among them was created (Figure 3). Numerous firms commenced on relocating their Shanghai-based headquarters to adjacent cites in consideration of markets and costs. On the other hand, various firms were also relocated from nearby small cities to Shanghai due to various intentions. The competition within the city groups escalated gradually. The National Development and Reform Commission was able to publish the Yangtze River Delta Regional Planning back in May 2016. The entire region 
is segmented into Shanghai, a leader among other additional cities totalling five: Hefei city group, Hangzhou city group, Ningbo city group, Nanjing city group and Suxichang city group. With all cities being identified differently, they were equally assimilated in the Yangtze River Delta Regional Planning using new tactics, to increase their compatibility in the entire regional economy and equally hasten Shanghai's development. For instance, the Hangzhou city group comprises of Huzhou, Hangzhou, Shaoxing and Jiaxing. Since Hangzhou has been associated with the preceding long past of electronic commerce, Alibaba's headquarter is located in Hangzhou and then the city's objective is becoming a global e-commerce assimilated hub. Generally, Huzhou entails prospered ecology resources and therefore it has the desire to become the state-wide leader of the ecology sector. Both Shaoxing and Jiaxing equally entail their individual distinguished plans as well.

\subsection{Siphon effect}

Apart from rivalry among small cities, HSR urbanisation has equally been subjected to rivalry from the central city within the area. During the late ' 90 s, the erection of road infrastructure was frequently considered with the aim of solving the agricultural product's procurement issues. However, this impact was considerably decreasing progressively and it occurs particularly in some economically deprived regions. From 1997 to 2006, Chinese peripheral cities were incorporated in the highway network and characterised by a drop in economic growth by $18 \%$ in comparison to the other peripheral cities, followed by a decrement in industrial output growth by a percentage of $26 \%$ lower than the average. While the highway was able to minimise the cost of transportation among areas, it was able to see that the industrial economy of the peripheral city continued to shift towards the city centre (Faber, 2012). During the HSR period, for huge cities and those operating as the transportation centres, such as Shanghai, Beijing and Shenzhen, HSR offers the expedient transportation. Nonetheless, they ought to possess firm power absorbing resources from adjacent smaller cities. On the other hand, for a number of small or middle-scale cities, there is still a limitation of the HSR-bought chances and passengers since most of the passers-by fail to halt at small cities. Due to this, HSR simply acts as a channel weighing them without any apparent progress in economy. Unfortunately, the bigger cities will definitely absorb the business opportunity and labour productivity. 'Polarisation' occurrence, equally identified as 'siphon effect' intellectually, frequently occurs when a small city goes head to head with an adjacent big city in terms of competition.

It establishes a condition of "constant weakness and constant strength." In consideration of the spatial shape, two forms of siphon effect exist. One is centralised while the other is linear. Conventionally, the Government of China was able to erect only HSR lines linking two major cities. Back then, these major urban centres were situated in two furthest ends and held the strongest siphoning capacity while the absorbing alignment commences from the central point towards the ends. Presently, the HSR grid's embryonic form has been established. Huge cities are linked to more small cities via diverse HSR lines, leading to huge siphon effect. A classical illustration of 'siphon effect' victims is Osaka in Japan. Subsequent to the commencement of operations of HSR Tokaido Shinkansen between Osaka and Tokyo back in 1964, Osaka was not able to improve its industrial structure or manage cooperation with other cities situated in the 
region. Due to this, the headquarters of several companies were relocated directly to Tokyo. At the beginning, a round trip between Osaka and Japan took eight hours. This needs the firms to retain their headquarters in Osaka upon opening fresh offices in Tokyo. Nonetheless, HSR was able to improve on speed thereby improving the ability to make a round trip on a daily basis thereby minimising the need to have two headquarters. Due to this, Osaka-based investments were siphoned to Tokyo, a larger city and a huge blow was subjected to the economy of Osaka. During the same era, the best illustration of increasing regional collaboration and avoiding 'siphon effect' could also be seen in Japan along with the identical lines. Therefore, at the inception of 'Tokaido Shinkansen' in Japan, Nagoya was simply not known to many people. Upon its assimilation into the 'Tokyo single hour metropolitan region', Nagoya, commenced the establishment of automobile manufacturing, textiles, electronics, trade as well as other cutting-edge manufacturing and modern services whereas Tokyo concentrated on becoming a financial hub and researched and designed headquarters. Presently, Nagoya is still the leading city in Japan's Chubu region. In Japan, Nagoya is the third largest city besides being the fourth most populated urban city in the whole country.

China has already been highly influenced by this siphon effect. For example, from a bigger scale, the larger cities with additional national advantages have commenced on absorbing Wuhan, but in 'Wuhan city circle', several chances from adjacent small cities have been absorbed by it as of the HSR operation (Cuijun, 2011). Wuhan city group comprises of Wuhan among other eight minor cities around it while Wuhan calls all the shots (Figure 4). Intercity railways defined by minimal speeds such as HSR $(250 \mathrm{~km} / \mathrm{h})$ were erected to link small cities with Wuhan. With reference of Wuhan's statistics from 2010 to 2015, there is an increment in Wuhan city group's population at a margin of $0.47 \%$ (from $52.83 \%$ to $53.3 \%$ ) of the whole population for the entire province. Nonetheless, this increment was only seen in Wuhan, with the other eight minor cities facing a decrement. From an economic point of view, only Wuhan's GDP escalated annually with the other eight cities that witness a varying GDP proportion decrease for those five years.

Figure 4 Wuhan city group population GPD (see online version for colours)
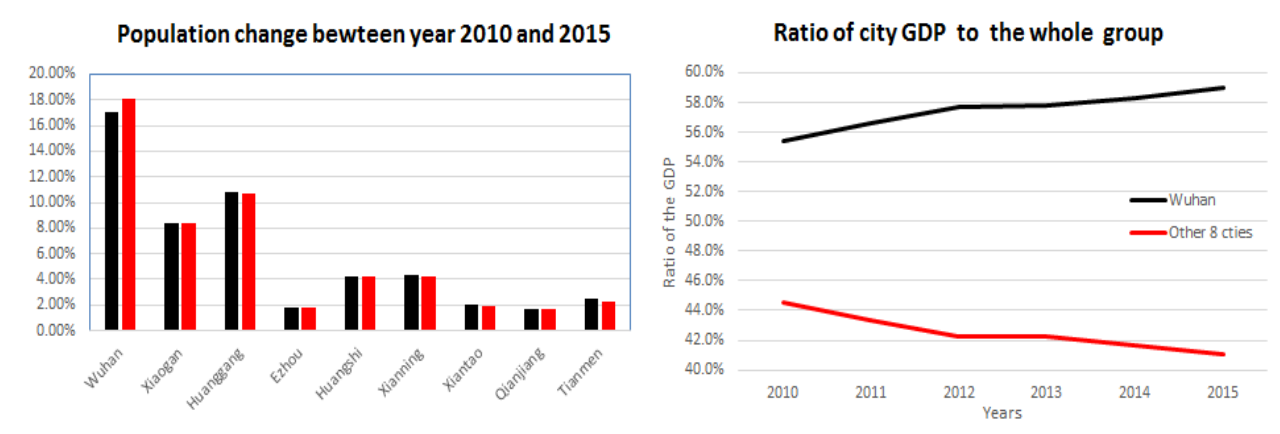

Source: Statistics from Hubei Bureau of Statistics, elaborated by the authors 


\subsection{Characteristics of the HSR station}

\subsubsection{Accessibility from the old city}

The affability distance between the original city and the HSR station is a key factor worth being considered. It is inconvenient for inhabitants in novel HSR cities to use the public service in the old districts as the counterpart in HSR cities is not mature. Then their preference would remain on the original city leaving the novel HSR city to become a ghost city eventually. As the HSR line has been launched in 2012, it only takes one hour from Dezhou East station to Beijing (capital of China) via HSR. However, it still requires an hour to move from the original downtown to Dezhou East station via public means, thereby decreasing the convenience of passengers. The novel HSR city of Dezhou covers an area of $56 \mathrm{sq}$. km. being strategised to a city as "primed by technology and aptness for living". Nonetheless, the expected positive impact of HSR fails to show up. The extensive distance complicates the linkage process of the traditional districts from the novel HSR zones or HSR cities (Figure 5). The dwellers in the novel HSR city have to consume a lot of money and energy to exploit the public service in the old districts. A limited number of residents are interested in procuring apartments in the new HSR district. A significant number of limited consumers are rather speculative than ideal users. Subsequently, the real estate projects are lowly priced and fail to bring the local government enough revenue with land selling. Dezhou's Government revenue was only 150 billion in 2013 and thereby it is really difficult for them to erect the HSR with the low land price. As a result, the cash flow is cut off and the whole plan is paralysed now.

Figure 5 Dezhou HSR urban development (see online version for colours)

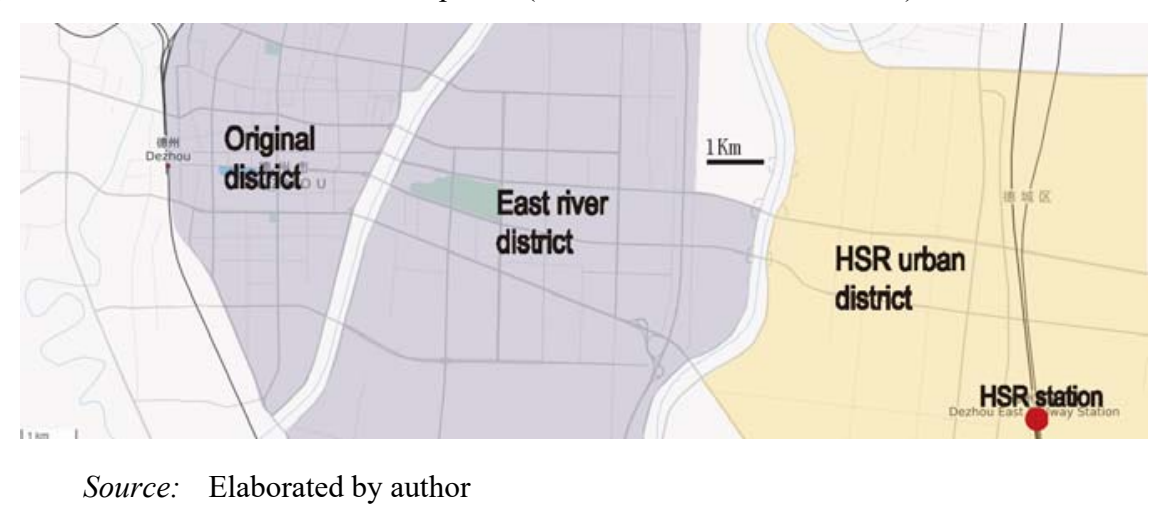

HSR stations can be erected barely in the old downtown. Generally, the inventive train station in a city has turned out to be the landmark or centre. Erecting the novel HSR station in the original station place also needs huge amounts of capital in order to carry on house demolition and relocate. By being engaged in a mechanical perception, the HSR train requires 'minimal turning radius' so as to avoid derailment during directional negotiations. An HSR train characterised by a speed of $350 \mathrm{~km} / \mathrm{h}$ needs a radius of 
7,000 metres while that with 250 or $300 \mathrm{~km} / \mathrm{h}$ needs a radius about $4,000 \mathrm{~m}$. There is a direct relationship between speed and radius, with a higher speed and a lengthy turning radius, which makes many HSR lines move via cities from outskirts or even farther places. Thus, the preference of a straight and long-distance route is the favourable choice. The proximity of any HSR station in big cities is close to the original city compared with minor cities mainly due to a highly administrative right for the big cities to enable the HSR location to manage its own urban space and growth. For middle or small cities, HSR stations are deemed to deviate the original city centre. For the impact of the distance between HSR stations and inventive city centres, the number of Chinese researchers has increased as far as its vague literature is concerned. Arguably, there is an inverse proportion between the city size and the distance ratio; in that, a small city will have a huge ratio between the distances from HSR stations to downtown with the city scale.

As a highly scientific index, this ratio is utilised to determine whether the distance from HSR to downtown is far or not. In their study, Zhao and Chen (2015) invented a formula to delimit this relative distance, where $Q$ symbolises the HSR's relative distance; $d$ stands for the ideal distance to HSR stations from the city centre, while $p$ is indicative for the area occupied by the inventive city. For the smaller cities, the relative distance is considered quite longer. The researchers were able to indicate that any relocation of 0.5 to 1 would make the HSR urbanism survives and as a result, the original city's development increases. This distance is in most cases not established by the local authorities, although there are various additional strategies that are considered in decreasing its impact and increasing the approachability of HSR cities. Shanghai hosts several metro lines linking the HSR station to the city centre. The number of cities utilising the bus liners in offering a solution to this issue has gone up. For instance, the station located in Dezhou east is characterised by five bus lines linking HSR stations with the rest districts. Each line is comprised of above 40 stops. In addition to this, trams and shuttle buses are planned in numerous cities.

\subsubsection{Connecting to the whole HSR network}

In accordance with Chinese Regulations on Railway Technology Management, there are four categories defining railway stations. Ideal class stations require 60,000 passengers on a daily basis to get off, get on or transfer. This number of first-class stations is roughly 15,000 with the second class stations accommodating 5,000 passengers. Fewer people are indispensable by the third class stations which can accommodate more than 2,000 passengers. The county-level cities host third class stations as the considerable number of HSR stations. This is to say that the total number of passengers in these stations on a daily basis is not more than 5,000. Prior to the design and erection of the station, there was a comprehensive prediction of the passenger flow so as to always have the station's capacity aggrandised. As Hilmola (2010) stated, the factors regarding the efficiency of railway transportation are still not accurately studied. A typical example of this condition is the Wuhan city group's intercity railway system. During the first day of Wuhan-Xianning railway operation, a total of ten-train couples operated between the two cities. Nonetheless, upon subsequent operations for a number of months, the rate of habitation remains only $50 \%$, thereby necessitating the decrement of these trains to seven couples. 
Zhuzhou and Shijiazhuang are two cities characterised by unique railway systems. As Hebei province's capital, Shijiazhuang covered an area of less than $0.1 \mathrm{sq}$. km at the onset of the 20th century. Upon an intersection of railways occurring in this city, Shijiazhuang is a huge city. Besides, Zhuzhou was sometimes backed by a town located in Yintan's county-level city but later tuned out to become Hunan province's second largest prefecture-level city upon operation of numerous railways. Nonetheless, in consideration of the HSR period, it is improbable for such wonders to take place since all the HSR systems deal with the prevailing provincial capitals compared with normal cities. The novel key HSR travels to Changsha city directly when compared with Zhuzhou city. From another angle of perception, within the HSR era, the linkage of a single HSR station is normally defined by the identity of the inventive city. A number of huge cities are defined by intersection of HSR capable of creating benefits although several such small cities simply entail a single HSR linking then to the network.

\section{Conclusions}

This study has successfully evaluated China's HSR urbanism development. The key constraints of HSR urbanism developments resulting in the 'ghost city' phenomena have been comprehensively underscored. It has been confirmed that HSR erection is directly associated with the success of embracing the transportation sector and regional growth appears, hence the notable need by several prevailing Chinese ghost cities aboard the scheduling of HSR erection. Throughout the comparison of various cities and towns in China subjected to the HSR railway network, this study has comprehensively outlined several approaches to ghost urbanisation that is extensively evident across China. This study also reveals extreme urbanisation patterns driven by aesthetic norms and political constraints, embracing logics dissimilar from those of market rationalities or populace densities. The 'HSR urbanisation technique' is perilously attached together by the supposition that the erection of urban landscape will ultimately give rise to urbanisation through enticing fiscal investment and inhabitants. Ghost cities have been exemplified as the material products of an ineffective conjuring trick. Instead of continuing the urbanisation process that has produced many ghost cities, it is imperative to come up with a novel framework and vocabulary that will more usefully describe conditions and guide planning. Such articulation will help relieve the disquiet that currently affects the aspirations of Chinese citizens for prosperous development. Future research should focus on empirical evidence and case studies that illuminate the origins and dynamics of the creation of ghost cities and the key actions that promote the desired development more scientifically.

\section{Acknowledgements}

This paper is supported by China Scholarship Council 201607820005. PhD candidate Sun Jing offered information about HSR cities and Eman Abdel Sabour helped on the diagram drawing. 


\section{References}

Allin, S. (2011) 'A new understanding of formal land use plans in Germany', International Journal of Sustainable Society, Vol. 3, No. 4, pp.385-396.

Banister, D. and Berechman, J. (2000) Transport Investment and Economic Development, UCL Press, London.

Bao, X. (2014) “一张图看清内地36座高铁新城: 多地已成鬼城 [36 HSR cities have become ghost cities]', Southern Weekly [online] http://finance.ifeng.com/a/20140817/ 12941083 0.shtml.

Brotchie, J. (1991) 'Fast rail networks and socio economic impacts', in Cities of the 21st Century: New Technologies and Spatial Systems', Longman Cheshire, New York.

Chi, G., Liu, Y. and Wu, H. (2015) 'GGost cities', analysis based on positioning data in China', Computer Science [online] https://arxiv.org/abs/1510.08505.

China, M. of L. and R. (2014) 关于推进土地节约集约利用的指导意见 (The Guidance of Land Conservation and Intensive Use [online] http:/www.mlr.gov.cn/zwgk/zytz/201409/ t20140926_1331065.htm.

Commision, C.N.D.A.R. (2016) 长江三角洲城市群发展规划 [Development Planning of Yangtze River Delta Urban Agglomeration].

Cuijun, L. (2011) ‘高铁效应对武汉发展的影响分析 [Analysing the HSR effect on Wuhan City]', Pioneering with Science \& Technology Monthly, No. 7, pp.3-5.

da Conceicao, A.L.M. (2015) From City's Station To Station City - An Integrative Spatial Approach to the (Re)Development of Station Areas, PhD Thesis, TU Delft, Architecture and the Built Environment, A+BE | Architecture and the Built Environment, Delft, ISBN 9789461864093.

Doulet, J. and Delaunay, T. (2016) 'Taking advantage of a historic opportunity? A critical review of the literature on TOD in China', Journal of Transport and Land Use, Vol. 10, No. 1, pp.1-16.

Faber, B. (2012) 'Trade integration, market size and industrialization: evidence from China's national trunk highway system', Review of Economic Studies, Vol. 81, No. 3, pp.1046-1070.

Florida, R. (2002) 'Book review: class distinctions for the global economy', Entrepreneurship and Innovation, February, February, Vol. 4, No. 1, pp.73-74.

Givoni, M. (2006) 'Development and impact of the modern high-speed train: a review', Transport Reviews, Vol. 26, No. 5, pp.593-611.

Hilmola, O-P. (2010) 'Analysing global railway passenger transport through two-staged efficiency model', International Journal of Information and Decision Sciences, Vol. 2, No. 3, pp.273-284.

Ishikawa (1985) 'The regional adaptation of high-speed rail system', The Annuals of City Studies of Japan, Vol. 18, No. 3, pp.14-19.

Jin, X. et al. (2017) 'Evaluating cities' vitality and identifying ghost cities in China with emerging geographical data', Cities, Vol. 63, pp.98-109 [online] http://linkinghub.elsevier.com/retrieve/ pii/S026427511630261X.

Nakamura, H. and Ueda, T. (1989) 'The impacts of the Shinkansen on regional development', in Transport Policy, Management \& Technology Towards 2001, Western Periodicals Company.

Pedro, M.J.G. and Silva, J.d.A.e (2013) 'A contextual analysis of the impacts of high speed rail on regional development and mobility', 13th WCTR, pp.1-20.

Puga, D. (2002) 'European regional policies in light of recent location theories', Journal of Economic Geography, Vol. 2, No. 4, pp.373-406.

Sands, B.D. (1993) The Development Effects of High-Speed Rail Stations and Implications for California, Institute of Urban and Regional Development, University of California, Berkley, California.

Shepard, W. (2015) Ghost Cities of China, Zed Books, London, UK. 
Standard Research Institute (2016) 中国大陆城市“鬼城”指数排行榜 (2015) [The Top 50 Ranking of Ghost Cities in Mainland China].

Storper, M. and Scott, A.J. (2009) 'Rethinking human capital, creativity and urban growth', Journal of Economic Geography, Vol. 9, No. 2, pp.147-167.

Vickerman, R. (1997) 'High-speed rail in Europe: experience and issues for future development', The Annals of Regional Science, Vol. 31, No. 1, pp.21-38 [online] http://dx.doi.org/10.1007/ s001680050037\%5Cnhttp://link.springer.com/10.1007/s001680050037.

World Bank (2014) Regional Economic Impact Analysis of High Speed Rail in China, Main Report, Washington, DC, World Bank [online] https://openknowledge.worldbank.org/handle/ 10986/19996 License: CC BY 3.0 IGO.

Zhao, Q. and Chen, G. (2015) “高铁站区位对站点周边开发影响的实证研究 [The influence of the HSR location on its peripheral development]', Urban Planning, Vol. 39, No. 7, pp.50-55 . 